\title{
Lightning Protection for Explosive Facilities
}

\author{
M. Ong
}

December 1, 2001

U.S. Department of Energy

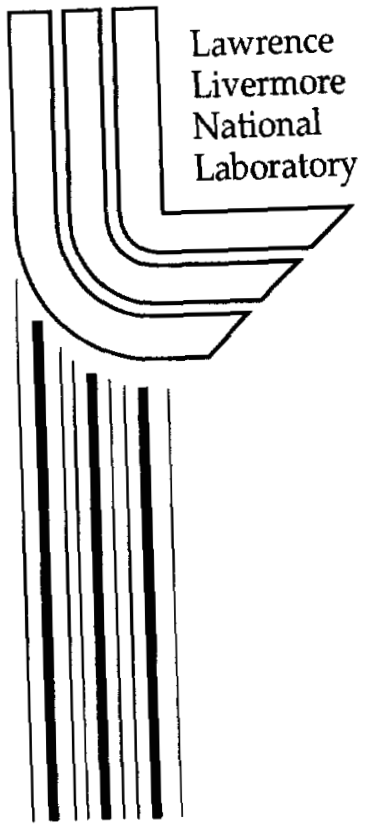




\section{DISCLAIMER}

This document was prepared as an account of work sponsored by an agency of the United States Government. Neither the United States Government nor the University of California nor any of their employees, makes any warranty, express or implied, or assumes any legal liability or responsibility for the accuracy, completeness, or usefulness of any information, apparatus, product, or process disclosed, or represents that its use would not infringe privately owned rights. Reference herein to any specific commercial product, process, or service by trade name, trademark, manufacturer, or otherwise, does not necessarily constitute or imply its endorsement, recommendation, or favoring by the United States Government or the University of California. The views and opinions of authors expressed herein do not necessarily state or reflect those of the United States Government or the University of California, and shall not be used for advertising or product endorsement purposes.

This work was performed under the auspices of the U. S. Department of Energy by the University of California, Lawrence Livermore National Laboratory under Contract No. W-7405-Eng-48.

This report has been reproduced directly from the best available copy.

Available electronically at http://www.doc.gov/bridge

Available for a processing fee to U.S. Department of Energy And its contractors in paper from

U.S. Department of Energy

Office of Scientific and Technical Information

P.O. Box 62

Oak Ridge, TN 37831-0062

Telephone: (865) 576-8401

Facsimile: (865) 576-5728

E-mail: reports@adonis.osti.gov

Available for the sale to the public from

U.S. Department of Commerce

National Technical Information Service

5285 Port Royal Road

Springfield, VA 22161

Telephone: (800) 553-6847

Facsimile: (703) 605-6900

E-mail: orders@ntis.fedworld.gov

Online ordering: http://www.ntis.gov/ordering.htm

\section{OR}

Lawrence Livermore National Laboratory

Technical Information Department's Digital Library

http://www.llnl.gov/tid/Library.html 


\title{
Lightning Protection for Explosive Facilities
}

\author{
Mike Ong \\ Lawrence Livermore National Laboratory \\ December 2001
}

\section{Introduction}

Lawrence Livermore National Laboratory funds construction of lightning protection systems to protect explosive processing and storage facilities. This paper provides an intuitive understanding of the lighting risks and types of lightning protection available. Managers can use this information to decide if limited funds should be spent constructing a lightning protection system for their own facilities. This paper answers the following questions:

1. Why do you need lightning protection systems?

2. How do lightning protection systems work?

3. Why are there no documented cases of lightning problems at existing explosive facilities?

Most people are not familiar with the lightning protections concepts like Faraday cages and stand-off distances. However, more people understand how to protect themselves from lightning storms, especially if they are involved with outdoor activities. The U.S. National Weather Service (NWS) provides very good information about lightning safety. The safety guidelines are easy to understand and available on the internet. I suggest spending a few minutes there (http://www.lightningsafety.noaa.gov/overview.htm) because the guidelines for protecting people also apply to facilities. This paper will explain facility lightning protection by drawing from the guidelines for protecting people. Hopefully this personal approach will make the concepts easier to understand and remember.

The first seven topics covered by the National Weather Services are:

1. Lightning - The Underrated Killer

2. Lightning Safety Awareness - An Educational Problem

3. Beware of A Developing Thunderstorm

4. The Lightning Discharge - Don't Be A Part of It

5. An Approaching Thunderstorm - When Should I Seek Safe Shelter

6. Outdoor Activities - Minimizing The Risk of Being Struck

7. Indoor Activities - Things to Avoid

These topics for protecting people will be mapped onto concepts for shielding explosive processing and storage facilities. The first topic, "Lightning - The Underrated Killer", will be covered in the next section, The Risk. Lightning safety awareness is important enough to deserve its own section. The third and fifth topics, "Beware of ... Thunderstorm" and "... When Should I Seek Safe Shelter", will be covered by the section on Lightning Warning Systems. The fourth and sixth topic, "The Lightning Discharge - Don't Be A Part of It" and "Outdoor Activities ...", will be combined in our 
section on Facility Lightning Protection Systems. The last topic, "Indoor Activities Things to Avoid", is covered by Penetrations, Electrical Wires, and Communications Lines.

\section{The Risk}

According to the NWS, in the United States, there are an estimated 25 million cloud-to-ground lightning flashes each year. During the past 30 years, lightning killed an average of 73 people per year in the United States based on documented cases. While documented lightning injuries in the United States average about 300 per year, undocumented injuries caused by lightning are likely much higher.

The facts are lightning strikes occur more often than we realize. Twenty-five million is a very big number. The consequences of lightning strikes to people are extremely serious, and fortunately rare.

Very few people have seen lightning strike a facility. So, it appears they are rare events based on direct observations. This makes sense because explosive facilities occupy an extremely small area compared with the landmass of the earth. However, the facilities are large compared with trees or people, often taller than surrounding objects, and have metal components, and therefore they are attractive to lightning. There is little data indicating how often explosive handling facilities are struck by lightning. From our examination of the lightning protection systems for these types of facilities, it appears that they have been struck by lightning. We have noticed lightning rods with burn marks. Therefore, it is not hard to believe that a very small number of explosive storage and processing facilities have been struck by lightning. So, anecdotally, we know that facilities are struck, and even though these are rare events. So, why haven't we had explosions?

If a person can be killed by a lightning strike, it should not be hard to believe that lightning currents can ignite some explosives. A lighting strike could carry currents as high as a couple hundred thousand amperes. Most of the modern detonators for setting off explosives will operate at a few amperes. Although some modern high explosives, $\mathrm{HE}$, cannot be ignited by lightning, many can. In general, lightning current and explosive components don't mix well.

We know that there are rare lightning strikes to explosive handling facilities. We know that lightning current can detonate explosives. So, what is protecting our facilities? In the following section, I will try to explain how we have consciously or fortuitously separated the current from our explosives.

\section{Lightning Safety Awareness}

According to the NWS, the lack of understanding about the dangers of lightning to the public continues to be a significant problem in the United States. Many people don't act to protect their lives, their property, and the lives of others in a timely manner simply because they don't understand all the dangers associated with lightning. The first step in solving this problem is to educate people so that they become aware of their 
behavior that puts them at risk of being struck by lightning, and to let them know what they can do to reduce that risk.

A similar statement can be made about protecting explosive facilities from lightning strikes. Managers for explosive operations seem to be better educated. But I think they still need the latest information about lightning protection so they can understand the risk and possibly reduce it further with only minimal effort.

There are many ways to reduce the chance of lightning induced explosions. Three of the more important ones are: (1) During a storm move the vulnerable components to a safe location. (2) Work in a lightning-proof facility. (3) Improve or replace older explosive components so they are less vulnerable to lightning.

Constructing an elaborate and expensive lightning proof facility cannot always be justified. Even if the best lightning protection system is not added to a facility, it is important to understand there many options to enhance safety. Possibilities include protecting only a portion of a facility or changing some work habits. Sometimes small procedural modifications can produce significant benefits. Understanding the lightning threat will motivate operators to act. At the least, more knowledge will prevent people from making the situation worse. Educating workers and managers about lightning safety produces benefits for both facilities and people. Lightning safety awareness ought to be encouraged.

\section{Lightning Warning Systems}

According to the NWS, thunderstorms are most likely to develop on warm summer days and go through various stages of growth, development and dissipation. On a sunny day, as the sun heats the air, pockets of warmer air start to rise in the atmosphere. When this air reaches a certain level in the atmosphere, cumulus clouds start to form. Continued heating can cause these clouds to grow vertically upward in the atmosphere into "towering cumulus" clouds. These towering cumulus may be one of the first indications of a developing thunderstorm.

The NWS warns that lightning can strike as many as 10 miles away from the rain area in a thunderstorm. Ten miles is about the distance that you are able to hear the thunder from the storm. In some instances when a storm is ten miles away, it may even be difficult to tell that a storm is nearby. However, if you can hear the thunder from a storm, chances are that you are within the striking distance of that storm. If the sky looks threatening, personnel should take shelter even before they hear thunder.

An early lightning warning is important because people need time to find safe shelter. Operators also need time to think about and to modify their work procedure to minimize risk. It's difficult for human observers to provide warning sufficiently early. Lightning detection and warning systems can be purchased that will give ample warning time. It is impossible to always predict the correct location and timing of storms with lightning. For the warning systems to be very effective, they will produce some false warnings. Lightning storms or the threat of them typically increase operational costs 
because certain operations must be postponed until the storm passes. However, with an appropriately protected facility, some of these risky operations could be safely performed during a storm. It would reduce operational cost.

The justification for having a lightning warning system and lightning protection system ought to be based on careful consideration a number of factors. They include the effectiveness of the safety systems, the impact on operations, the consequences of an explosion, the probability of it happening, and the total cost. Chance is at play here.

The lightning threat and other safety threats have some probability of occurring. The consequences are somewhat different. Their costs are different. These comparisons to decide what safety system should get priority is beyond the scope of this paper.

\section{Facility Lightning Protection Systems}

The NWS very clearly explains how to protect yourself from lightning. Don't be a part of the lightning discharge. Each flash of cloud-to-ground lightning is a potential killer. The determining factor on whether a particular flash could be deadly depends on whether a person is in the path of the lightning discharge. In addition to the visible flash that travels through the air, there is an associated current that travels along the ground. Although some victims are struck directly by the main lightning stroke, many victims are struck as the current moves in and along the ground. The greatest number of lightning deaths and injuries in the United States occurs during the summer months when the combination of lightning and outdoor summertime activities reaches a peak.

For many organizations it is impossible to build a facility only in locations that are lightning free. There may be a choice of picking a valley location that is safer rather than a hilltop. Because thunderstorms are more likely during some parts of the year, operational schedules could be adjusted to minimize this seasonal threat. Given we want to implement lightning safety, our course of action must be to remove ourselves from the lightning discharge path.

We have at least three common options for diverting the current away from us. The goal is to surround the area needing protection with a metal box or boxes. These boxes are sometimes called "Faraday" cages. For currents that change very slowly, the voltage everywhere inside the cage is about the same. Interior voltages for the faster changing lightning current will be higher and the levels will depend on the quality of the cage. A box with tightly interconnected metal sheets is better than one constructed with widely spaced wires. In general, the more metal the lower the voltage. The cages can be used singly or in combination. We will start with the outermost option.

(1) A catenary system is a tent of wire hung over and around a facility. It should intercept lightning bolts and divert current away from the facility and into the earth. Because it is a poor "Faraday Cage", the voltages on the wires can be quite high. To prevent secondary arc formations, the facility must be widely separated (tens of feet) from the catenary wires. 
(2) A steel reinforced (rebar) concrete structure can be turned into a "Faraday cage". This approach requires the roof, walls and floor to be electrically connected. The current flows on the rebars from the strike point into the earth. If the explosive component is electrically isolated from the building lightning current cannot flow through the explosives. If a component is touching the facility in only one place, current cannot flow out if the "return" path has sufficient separation from the facility. Generally it is better to keep both wires of a detonator away from the rebar in a building. For a reasonably good rebar "Faraday" cage, typical separation distances are inches to about a foot.

(3) A metallic weapon case can also divert lightning current around critical components inside. Modern nuclear weapons are designed this way. "Faraday" cages may be metal shipping containers. The quality of these "Faraday" cages will vary greatly. Nonetheless, the same requirements for isolation must be met. The critical component must not touch the case or touch it only in one place.

The level of the protection that these boxes must provide is difficult to quantify because typically they are inside a shelter. Even a poor "Faraday" cage facility will sufficiently reduce the threat inside. So, even if weapons cases were to become a part of the facility cage, only a small fraction of the lightning current would flow on the weapon "faraday" cage. While multiple layers of lightning protection are desirable, their interactions make analysis of the problem much more complex.

In addition, lightning rods with down conductor system should be mentioned because they are the standard way to protect facilities. The rods are appropriate for protecting wooden structures to keep them from catching fire when struck by lightning. However, when used with a reinforced concrete building, they make little sense. The rebar will carry most of the current rather than the down conductors. So, money is better spent constructing a good "Faraday" cage.

When designed and constructed correctly, these three types of barriers with appropriate separation distances will divert current around the objects that we are trying to protect. They are not perfect and some voltage will be present in the barrier. The interior voltage levels can be estimated from the design information or low-power measurements. Once the maximum voltage is known, we can calculate isolation requirements between the barrier and the components so an arc will not develop.

The NWS makes an important point about people being killed by the currents in the ground not just from a direct strike. Lightning current can travel a very long distance, especially if there are metal pipes in the ground. These metallic objects can penetrate our lightning barriers and negate any protection. For example, electrical conduits very often pass under catenary systems. Water lines frequently penetrate facilities from below. Even the integrity of weapons cases may be compromised with arming wires that pass 
from the outside to the inside. The problems that these penetrations create and solutions will be covered in the next section.

Why are there no documented cases of direct lightning initiated explosions in a US facility?

At this point, we should have some insight about why there have been no documented lightning-initiated explosions in the U.S. Most organizations put their critical components into a safe location when the weather is threatening. These safe locations are rarely struck by lightning. Even when the facility is struck, the vulnerable components have been situated so they don't touch the walls containing the lightning current. Even without official lightning protection systems, we may in fact have barriers with various degrees of effectiveness. Most explosive facilities are constructed of reinforced concrete. Many times the explosive devices are in sturdy weapon cases, metal cans, or wooden boxes. We probably have sufficient isolation from our fortuitous barrier so the explosive components are not a part of the lightning discharge. For example, people know better than to leave the wires of detonators hanging out and touching facility walls or metal containers. We instinctively protect critical components. The cards have been stacked in our favor without much analysis and effort. However, I recommend a more systematic approach to controlling the lightning risk. At the very least, we should be conscious of the consequences and make a formal decision to accept the risk. We should not continue to depend on luck.

Where budgets are limited, we can still do many things that reduce the risk of an explosion. During a lightning warning, we could delay the more risky operations that expose explosives to lightning. If our facility is not a perfect "Faraday" cage, we might want to increase the separation distance from the wall and explosive components.

Detonations can be stored in sturdy metal containers with their leads isolated from the walls until they are needed. The more vulnerable components might be stored in a facility that is expendable, and we prevent people from entering that particular facility during a lightning warning condition. Risk reduction is limited only by our understanding of the problem and our creativity.

\section{Penetrations, Electrical Wires, and Communication Lines}

According to the NWS, inside homes, people must also avoid activities which put their lives at risk from a possible lightning strike. As with the outdoor activities, these activities should be avoided before, during, and after storms. In particular, people should stay away from windows and doors and avoid contact with anything that conducts electricity. People may also want to take certain actions well before the storm to protect property within their homes, such as electronic equipment.

Most explosive handling facilities do not have large windows. But they do have doors and vent openings. Because the metal may not be as thick or electrically well connected around these openings, the voltages around these openings might be higher. It would be prudent to increase the isolation distance around these weak spots. 
They also recommend avoiding contacting anything that conducts electricity. We already mentioned the problem with these penetrations. Lightning could strike a water line many hundreds of feet away and the current will follow the metal pipe into a facility. If the pipe passed through the "Faraday" cage without touching it, lightning current will be carried into the protected area. If the pipe is close to a detonator, an arc could form and carry current onto the wires. This is bad. To prevent most of the current from entering the building, the pipe must be electrically connected to the "Faraday" cage at the cage boundary. This bonding of metallic penetrations to the cage must be done for every type of electrical conducting "pipe". It includes electrical conduits, water lines, sewer lines, vacuum lines, vent stacks, and air lines.

It is not possible to bond every metallic penetration to the building. Examples are electrical power wires, telephone and other communication lines, and instrumentation and control circuitry. The wires must carry some voltage and cannot be shorted to the building. The well-known solution is to add surge suppressors to the lines. The highvoltage spike generated by a lightning strike is limited to a level a little more than the normal operating voltage. Many people understand that surge suppressors protect electronic equipment in a thunderstorm. Around explosive components, surge suppressors are even more important. By controlling the high-voltage pulse, arc formation is eliminated between these wires and an explosive component as long as an appropriate separation is maintained.

\section{Recommendations}

We have discussed qualitatively the lightning risk and the different protection schemes. A good place to get a general understanding of the risk to your facility is by reading the National Fire Protection Association (NFPA) 780 Standard, Appendix H, "Risk Assessment Guide". The next step is to determine how much protection is needed and the cost. Not everyone will need a high-performance facility-size "Faraday" cage with an early warning system. There are alternatives like protecting only a small facility or even just a room. It is possible to just put critical components away in a steel safe until the storm passes.

If you are going to embark on building one of the mentioned modern lightning protection barriers, it is very important to understand how they work and what the operational requirements are, e.g., separation distances.

While lightning has not yet directly initiated an explosion in a US facility, the physics tells us that it is possible. We have not had an explosion because of conscious effort at some facilities and the rest are just plain lucky. We should not continue to depend on luck.

May you never be a part of the lightning discharge. 